Preprint

UCRL-JC-144354-REV-1

\title{
Explosion in the Granite Field: Hardening and Softening Behavior in Rocks
}

\author{
I. N. Lomov, T. H. Antoun, L. A. Glenn
}

This article was submitted to $12^{\text {th }}$ American Physical Society Topical Group Conference on Shock Compression of Condensed Matter

Atlanta, GA

June 24-29, 2001

U.S. Department of Energy

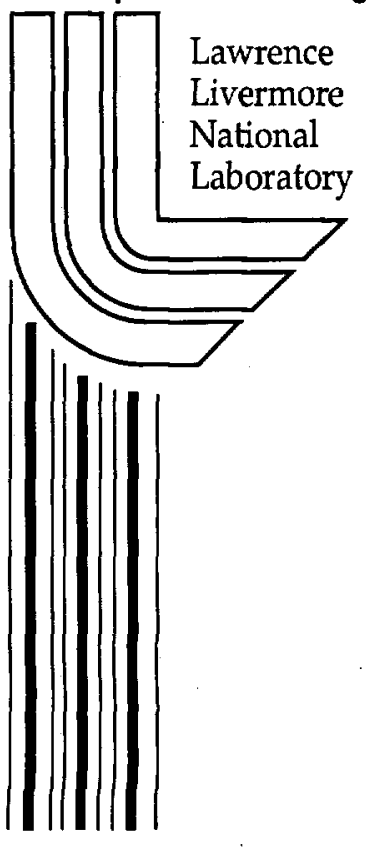

July 12, 2001 


\section{DISCLAIMER}

This document was prepared as an account of work sponsored by an agency of the United States Government. Neither the United States Government nor the University of California nor any of their employees, makes any warranty, express or implied, or assumes any legal liability or responsibility for the accuracy, completeness, or usefulness of any information, apparatus, product, or process disclosed, or represents that its use would not infringe privately owned rights. Reference herein to any specific commercial product, process, or service by trade name, trademark, manufacturer, or otherwise, does not necessarily constitute or imply its endorsement, recommendation, or favoring by the United States Government or the University of California. The views and opinions of authors expressed herein do not necessarily state or reflect those of the United States Government or the University of California, and shall not be used for advertising or product endorsement purposes.

This is a preprint of a paper intended for publication in a journal or proceedings. Since changes may be made before publication, this preprint is made available with the understanding that it will not be cited or reproduced without the permission of the author.

This report has been reproduced

directly from the best available copy.

Available to DOE and DOE contractors from the

Office of Scientific and Technical Information

P.O. Box 62, Oak Ridge, TN 37831

Prices available from (423) 576-8401

http://apollo.osti.gov/bridge/

Available to the public from the

National Technical Information Service

U.S. Department of Commerce 5285 Port Royal Rd., Springfield, VA 22161 http://www.ntis.gov/

OR

Lawrence Livermore National Laboratory

Technical Information Department's Digital Library

http://www.llnl.gov/tid/Library.html 


\title{
Explosion in the granite field: Hardening and softening behavior in rocks.
}

\author{
Ilya N. Lomov, Tarabay H. Antoun, Lewis A. Glenn
}

Lawrence Livermore National Laboratory, Livermore, California 94550, USA

\begin{abstract}
Properties of rock materials under quasistatic conditions are well characterized in laboratory experiments. Unfortunately, quasistatic data alone are not sufficient to calibrate models for use to describe inelastic wave propagation associated with conventional and nuclear explosions, or with impact. First, rock properties are size-dependent. Properties measured using laboratory samples on the order of a few centimeters in size need to be modified to adequately describe wave propagation in a problem on the order of a few hundred meters in size. Second, there is lack of data about the damage (softening) behavior of rock because most laboratory tests focus on the pre-peak hardening region with very little emphasis on the post-peak softening region. This paper presents a model for granite that accounts for both the hardening and softening of geologic materials, and also provides a simple description of rubblized rock. The model is shown to reproduce results of quasistatic triaxial experiments as well as peak velocity and peak displacement attenuation from a compendium of dynamic wave propagation experiments that includes US and French nuclear tests in granite.
\end{abstract}

\section{INTRODUCTION}

Modeling the dynamic response of rock materials is a challenging area of research. Since most strength measurements in rock materials are performed for intact samples under static conditions, the models based on these data should account for possible scale and rate effects when being applied to simulation of the dynamic response of large-scale rock masses. Unlike intact rock samples, rock masses may contain discontinuities that may reduce the strength.

Several attempts were made in the past to simulate wave propagation in rock media $[1,2]$. The standard approach was to optimize the model to reproduce wave profiles at several different ranges away from the source. The ability to reproduce specific characteristics of the profile (peak values, width, rebound phase, damping) was considered important for understanding the physics of the problem. However, experimental data show significant scatter even in wave profile measurements made at the same range, but at different azimuths for a single event. On the other hand, ensemble data of peak velocity and peak displacement attenuation for hard rock fall into a relatively small band. Hence, this data was chosen to be a reference for the model calibration in the present paper.

\section{THE CONSTITUTIVE MODEL}

The constitutive equations developed here are nonlinear, thermodynamically consistent, and properly invariant under superposed rigid body motions. The equations are valid for large deformations and they are hyperelastic in the sense that the stress tensor is related to a derivative of the Helmholtz free energy. We assume that the material is isotropic and apply the mathematical structure of plasticity theory to capture the basic features of the mechanical response of geological materials. The mathematical framework used to develop the model and a detailed description of the model equations can be found in [3].

The deviatoric behavior of the rock is described using an elastic-viscoplastic model, coupled with a damage model, and the volumetric behavior is described using an equation of state, coupled with a porous compaction and bulking model. Initial yielding is followed with a plastic strain hardening phase that persists until the loading path intersects the failure surface. Thereafter, damage accumulation causes gradual strength reduction from the failure surface down to a residual value equivalent to a small fraction of the undamaged strength. 
The equation of state, which describes the solid rock behavior, is supplemented with an analytic porous compaction model that describes the relationship between pressure and porosity. Also included in the volumetric behavior description is a dilatancy model that relates bulking to plastic distortion in such a way as to ensure thermomechanical consistency with the second law of thermodynamics.

\section{Strength of material}

As described in [3], the physical phenomena that influence the yield strength $Y$ are taken into account using a multiplicative form with $Y$ given by:

$$
Y=Y_{0} F_{0}(\xi, p) F_{1}(\xi, p) F_{2}\left(\varepsilon_{p}\right) F_{3}(\rho, \varepsilon)
$$

where $Y_{0}$ is the initial yield strength of the rock at zero pressure, the functions $F_{0}(\xi, p), F_{1}(\xi, p), F_{2}\left(\varepsilon_{p}\right)$, and $F_{3}(\rho, \varepsilon)$ respectively account for the effects of scaling, hardening, damage and melting on the strength and failure of the rock

In Equation $1, F_{0}\left(\varepsilon_{p}, p\right)$ is a scaling function equal to unity for intact rock samples and decreases monotonically as a function of pressure and inelastic deformation. This function was incorporated into the model because our simulation results showed that the yield and failure stresses measured statically using relatively small, defect-free samples had to be reduced to satisfactorily reproduce the dynamic data. This is in line with experimental observations that show the strength of granite and other geologic materials to be size-dependent, decreasing with increasing specimen dimensions.

$F_{1}$ is a hardening function expressed in terms of the hardening parameter $\xi$ as follows:

$$
F_{1}=1+\left(k_{1}(p)-1\right) \xi
$$

where $k_{1}$ is a function that expresses the relationship between the initial yield and the failure strength of the rock, both of which are varying functions of pressure as shown in Figure 1. The hardening parameter $\xi$ varies between 0 and 1 ; it is determined by an evolution equation of the form

$$
\dot{\xi}=k_{2}\left[\frac{\dot{\varepsilon}_{p}}{f_{1}(p)}\right](1-\xi)
$$

where $\dot{\varepsilon}_{p}$ is the plastic strain rate and $k_{2}$ is a model parameter. The pressure hardening function $f_{1}(p)$, which expresses the dependence of the yield strength on applied pressure, is determined from laboratory measurements on small rock samples [4].

The damage function $F_{2}$ controls the strength degradation of the rock after damage begins to accumulate. It is expressed in terms of the plastic strain, $\varepsilon_{p}$, using the simple relation

$$
F_{2}=\max \left\{\begin{array}{l}
1-k_{s} \varepsilon_{p} \\
\alpha p / Y(p)
\end{array}\right.
$$

where $k_{5}$ and $\alpha$ are model parameters, and $Y(p)$ is the pressure-dependent, but undamaged value of the yield strength. The function in Equation (2a) takes on values ranging between 1 for the intact material, and 0 for the fully damaged material. The function in Equation (2b) represents the residual strength of the damaged material. It is a linear function of pressure and it represents only a small fraction of the strength of the undamaged rock. The parameter $\alpha$ in this equation can be-viewed as the friction coefficient of the damaged material. A value of $\alpha=0.1$ was used in the simulations discussed here.

$F_{3}$ models the effect of material melting (i.e., thermal softening) near the source region.

\section{Porous compaction and bulking}

The total gas porosity is separated into two parts, $\phi_{1}$ and $\phi_{2}$

$$
\phi=\phi_{1}+\phi_{2}
$$

$\phi_{1}$ describes changes in porosity associated with the compaction of existing pores, whereas $\phi_{2}$ describes changes in porosity associated with bulking (increasing porosity under positive pressure) and it is proportional to the rate of dissipation due to plastic deformation.

Compaction of the porosity component $\phi_{1}$ is described using the modified $p-\alpha$ model [3].

The rate at which bulking may proceed is constrained by the second law of thermodynamics, which governs the entropy production of dissipative thermodynamic processes. The evolution of the porosity component $\phi_{2}$, which models the porosity due to bulking, is described using the following relation: 


$$
\begin{aligned}
\dot{\phi}_{2} & =(1-\phi) H\left(\phi_{2}\right) \times \\
& \times\left[\frac{m_{d} \sigma_{e f f} \dot{\varepsilon}_{p}\left\langle\phi^{*}-\phi_{2}\right\rangle}{\max \left(p^{*}, p\right)}-m_{c}\left(1-F_{2}\right)\langle-D \cdot I\rangle\right]
\end{aligned}
$$

In this equation, $\sigma_{e f f}$ is von Mises stress and $\dot{\varepsilon}_{p}$ is the plastic strain rate. $\phi^{*}$ is a model parameter that specifies the maximum bulking porosity that can be achieved, $m_{d}$ determines the rate of bulking and $m_{c}$ is used to control the rate of recompaction of the bulking porosity, a process that takes place only when the material is damaged and accelerates as damage increases and $F_{2} \rightarrow 0$.

\section{SIMULATION RESULTS}

Peak velocity and peak displacement measurements from deeply buried nuclear explosions [5] are shown in Figures 1 and 2. These data are assembled from events with 2 orders of magnitude yield range and do not exhibit significant scale dependence. The data shown in Figs. 1 and 2 are well represented by a linear fit in log-log space, with all the points falling within a factor of \pm 2 from the line. An automatic optimization procedure, based on this linear fit to the velocity and displacement data, was used to calibrate characteristic model parameters. The solid lines in Figs. 1 and 2 depict the simulated peak velocity and displacement attenuation as a function of slant range. This model is in good agreement with the ensemble of data shown in the figures, and is therefore believed to be a good representative of the overall behavior of granite. Hence this model can be used for predicting attenuation of shock waves in hard rock when specific information about the geology and material properties of the location of interest are unknown. Other possible applications of the model include studying several other effects like complex geologies, depth of burial and scaling.

Figures 3 and 4 show the results of a parameter sensitivity study that further illustrates some of the effects discussed in the preceding paragraphs. Specifically, these two figures compare the peak velocity and peak displacement attenuations simulated using the calibrated model with those simulated using a version of the model in which a specific feature is disabled. The effects of porous compaction, bulking, and scaling are investigated in this manner and as shown in the figures, each of these model features has a pronounced effect on the simulated response.

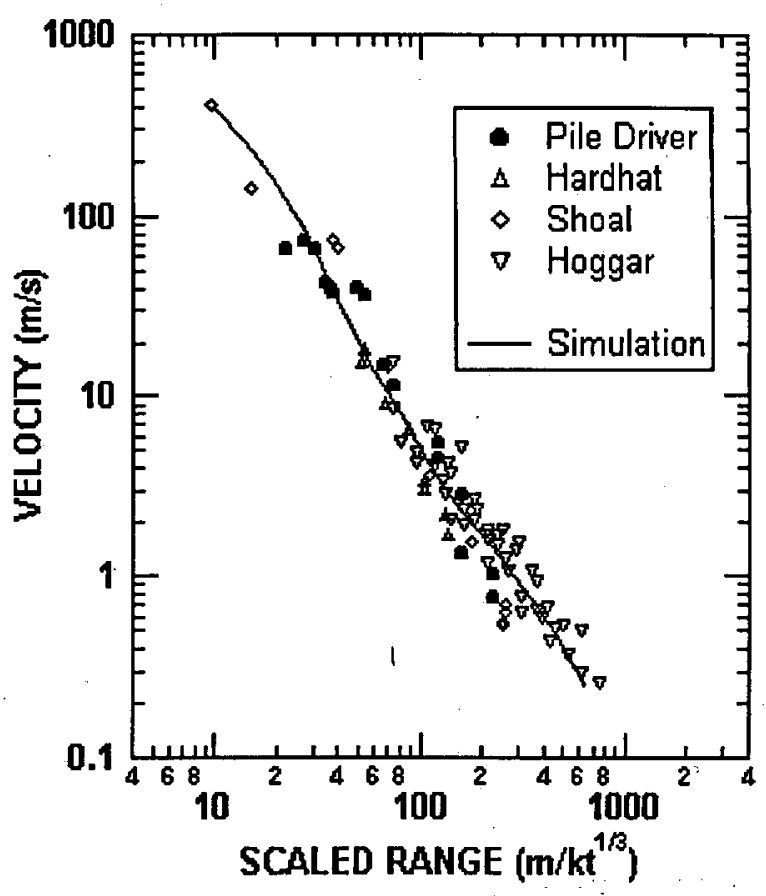

FIGURE 1. Comparison of simulated peak velocity attenuation with measurements from several spherical wave experiments in granite.

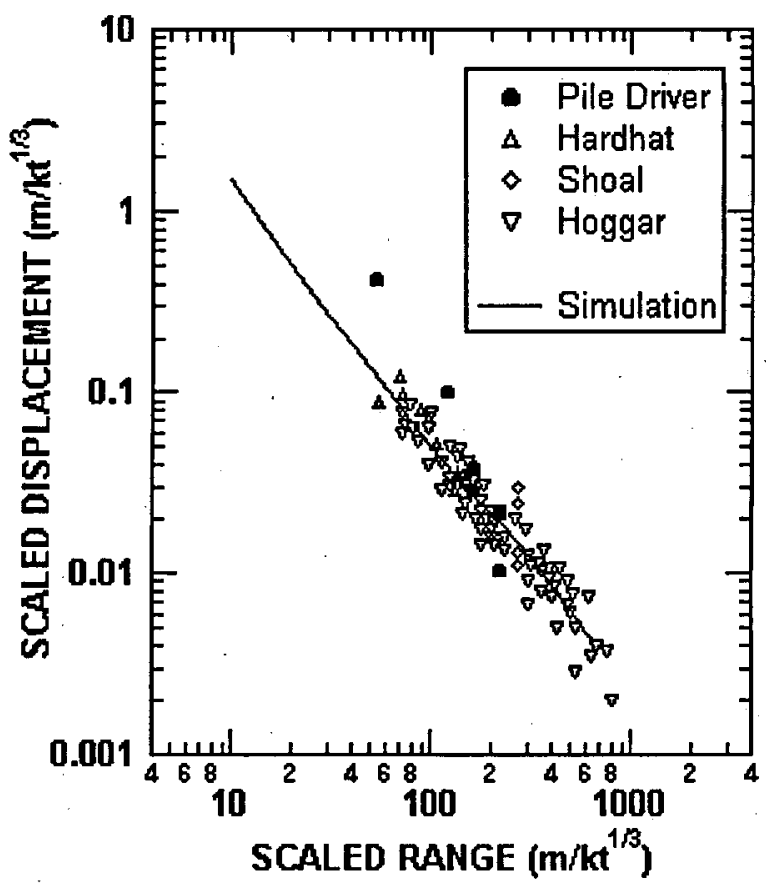

FIGURE 2. Comparison of simulated peak displacement attenuation with measurements from several spherical wave experiments in granite. 
Attempts to calibrate the model in the absence of any of these features were not successful because it was not possible to obtain good agreement with both peak velocity and peak displacement attenuation simultaneously. This emphasizes the fact that all of the seemingly complex model features are necessary for achieving a consistent description of the dynamic behavior of hard rocks.

Although the model has not been yet thoroughly validated for geologic materials other than granite, we believe that the model is sufficiently flexible that it can be used to represent the behavior of a wide range of geologic materials. This stems from the fact that the model incorporates many of the phenomenological features normally associated with the behavior of geologic materials.

\section{ACKNOWLEDGMENTS}

This work was performed under the auspices of the U.S. Department of Energy by the University of California, Lawrence Livermore National Laboratory under contract No. W-7405-Eng-48.

\section{REFERENCES}

1. Stevens, J. L., Rimer, N., and Day, S. M., "Constraints on Modeling of Underground Explosions in Granite," Report SSS-R-87-8312, S-Cubed division, Maxwell Labs, 1986.

2. Vorobiev, O.Yu, Antoun, T. H., Lomov I.N, Glenn, L.A, "A Strength and damage model for rock under dynamic loading", in Shock Compression in Condensed Matter1999, edited by S. C. Furnish et al., AIP Conference Proceedings 505, New York: American Institute of Physics, 2000, pp. 317-320.

3. Rubin, M.B, Vorobiev, O.Yu., Glenn, L.A., 2000, "Mechanical and numerical modeling of a porous elasticviscoplastic material with tensile failure," Int. J. Solids and Structure, Vol.37, pp.1841-1871.

4. Schock, R. N., Heard, H. C., and Stephens, D. R., 1973, "Stress-Strain Behavior of a Granodiorite and Two Craywackes on Compression to 20 Kilobars," $J$. Geophys. Res., Vol.78(36), pp. 5922-5941.

5. Heuze, F. E. Review Of Geomechanics Data From French Nuclear Explosions In The Hoggar Granite, With Some Comparisons To Tests In United States Granite. Report Ucid-19812, LLNL, 1983.

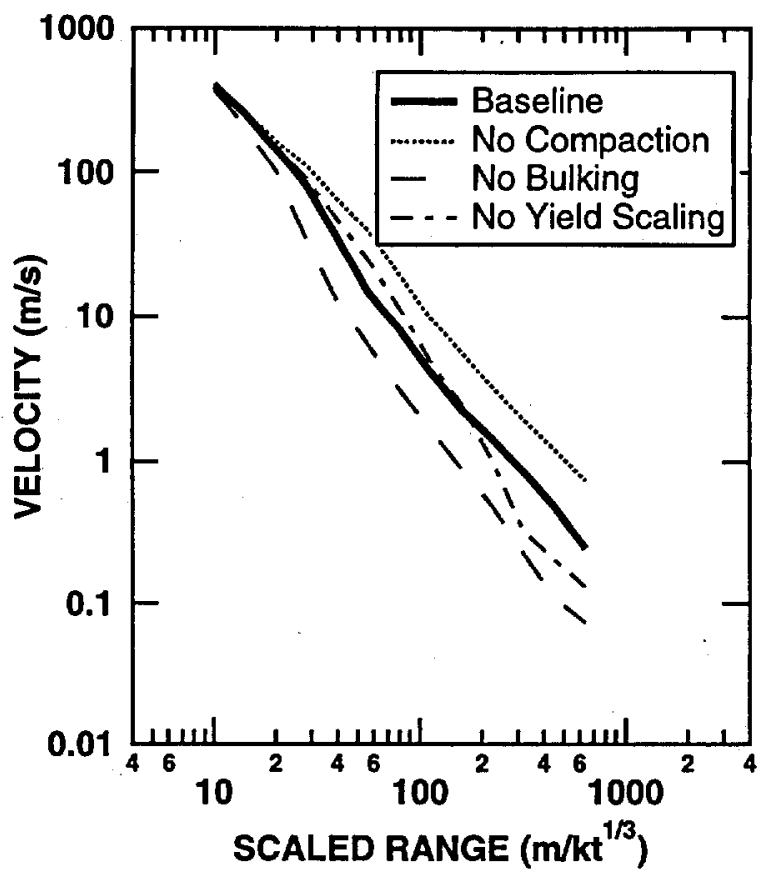

FIGURE 3. Effect of compaction bulking, and yield strength scaling on the simulated peak velocity attenuation as a function of scaled range

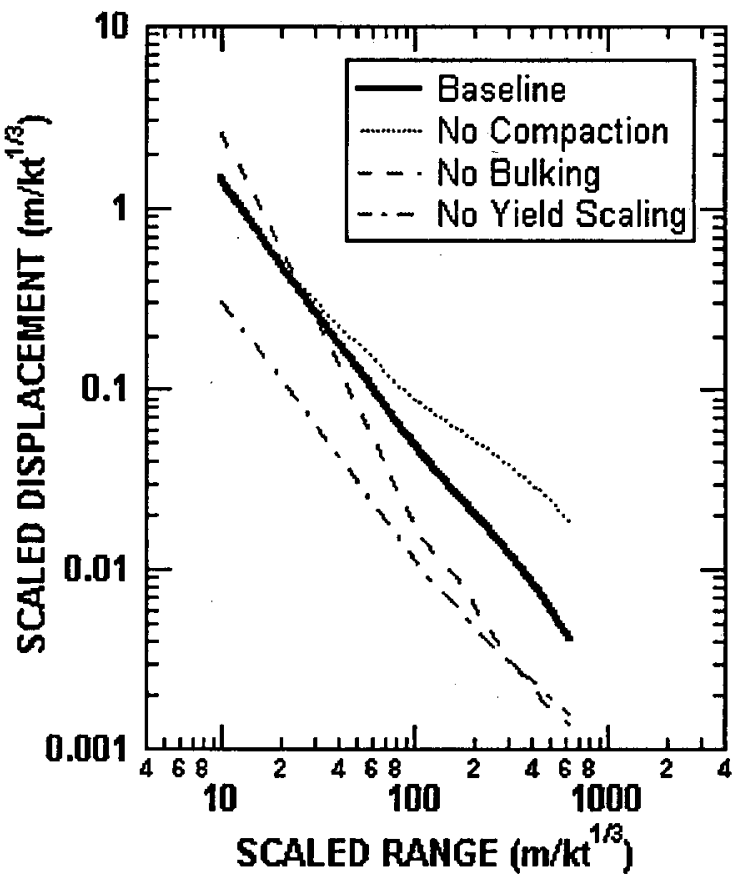

FIGURE 4. Effect of compaction bulking, and yield strength scaling on the simulated peak displacement attenuation as a function of scaled range. 


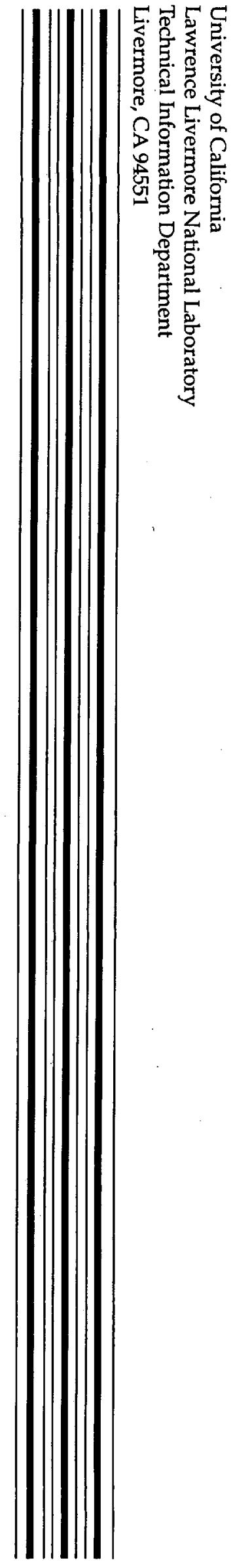

